\title{
Mirada foucaultiana a las tecnologías de control y poder circulantes en las iglesias protestantes.
}

\author{
Diana Manzanero-Márquez ${ }^{1, *}$ \\ ${ }^{1}$ Universidad Latina de Panamá, Panamá, República de Panamá. \\ *Autor para correspondencia. Email: dianamanzanero@gmail.com
}

Recibido: 24 de julio de 2015

Aceptado: 12 de agosto de 2015

\begin{abstract}
The aim of this article is to study evangelical discipline as a mean of control and power within the Protestant churches. Through a phenomenological qualitative study, we intended to approach the reality of six young evangelicals, members of a Venezuelan Pentecostal Evangelical Church. A focused interview was used to collect information, applying a Critical Discourse Analysis for the analysis of results. The final reflections were as follows: the young evangelical has as principle of life and faith, the Lord Jesus plan of salvation. Ecclesiastical discipline, unlike the biblical, is a mechanism of control and power that seeks to exercise dominion over the members of the church, and forces them to keep and establish a docility-utility relation with disciplinary authorities, using the speech as a mean for the exercise of such technologies.
\end{abstract}

Keywords: Evangelical discipline, technologies, power, control, protestant churches.

\section{Resumen}

El presente artículo está orientado al estudio de la disciplina evangélica como mecanismo de control y poder dentro de las iglesias protestantes. Fundamentado en un estudio cualitativo fenomenológico, se pretendió acercarse a la realidad de seis jóvenes evangélicos, miembros de una Iglesia Evangélica Pentecostal de Venezuela. Para recolectar la información se utilizó la entrevista focalizada, para el análisis de resultados, el Análisis Crítico del Discurso. Las reflexiones finales fueron las siguientes, el joven evangélico tiene como principio de vida y de fe, el plan de salvación de Señor Jesús. La disciplina eclesiástica, a diferencia de la bíblica, es un mecanismo de control y de poder que busca ejercer dominio sobre los miembros de la iglesia, los obliga a permanecer y establecer una relación de docilidadutilidad con las autoridades disciplinarias, utilizando el discurso como medio para el ejercicio de dichas. Palabras clave: Disciplina evangélica, tecnologías, poder, control, iglesias protestantes. 


\section{Introducción: Actualidad de la Iglesia Evangélica y los procesos disciplinarios.}

La creencia que Jesús vino a este mundo y murió por el hombre derramando su sangre en señal de pacto, ha sido difundida a través de los siglos, por diferentes hombres y mujeres, que han asumido ese fundamento de fe como suyo y han procurado compartirlo con todo aquel que les rodea. Asimismo, diferentes iglesias han surgido a raíz de la interpretación del libro base, de un nutrido grupo de religiones que existen alrededor del mundo: La Biblia; es así como se observa la diversidad de organizaciones existentes en el planeta que dicen ser cristianas, seguidoras de Cristo.

En La Biblia, dividida en Antiguo Testamento (AT) y Nuevo Testamento (NT), establece en el NT, que el término iglesia no necesariamente está restringido a reunión o congregación de personas, sino que tiene dos acepciones; una de carácter universal, ya que habla del conjunto de cristianos de todos los tiempos, y otra que designa lo mismo, pero con un sentido local, aquellos que se reúnen en un sitio. La concepción de la iglesia como un local o un edificio, se aplicó por extensión en períodos posteriores, pues con la ascensión al poder de Constantino (280-337d.c.), en el Imperio Romano, la situación del cristianismo cambiaría de manera radical, llegaría a convertirse en la religión oficial, al cristianizarse el Imperio. Con los Edictos de Milán y Tesalónica, el término iglesia no solamente va a estar vinculado a la comunidad cristiana como tal, sino que haría referencia en primer lugar al local o edificio donde se reunieran los creyentes a hablar de la Palabra de Dios (Álvarez, 1987; Vila y Santamaría, 1988).

Las iglesias creadas han ideado su propia organización, sus estatutos; doctrinas y dogmas se han originado partiendo de la interpretación de la Palabra de Dios. Es así como se han inventado toda una estructura organizacional, en cuanto a cómo debe funcionar la iglesia; han diseñado normas y reglas para el establecimiento de políticas que identifiquen y regularicen la vida del feligrés en ellas; de este modo la persona que decida enrolarse en sus filas y hacerse miembro, debe conocerlas para no incurrir en faltas, dicho de otro modo, para no pecar.

Dentro de las iglesias, específicamente en las evangélicas, se hace necesaria la presencia de un líder, que predique de las verdades y virtudes de La Biblia, al mismo tiempo que enseña el camino adecuado para seguir a Dios. Estos fundamentos de fe, casi siempre, aunque no lo admitan, se ven sesgadas por la visión de aquel que las interpreta; experiencias, sentimientos y pensamientos influyen de manera directa en el discurso predicado en la reunión semanal. En estas iglesias, los líderes o pastores son seguidos, aunque no por todos los miembros, fielmente en lo que propongan, ya que para ellos es la persona escogida por Dios para dirigirlos, por tanto lo que él diga es tomado como si Dios lo dijera. Es así, como en algunas congregaciones los pastores son vistos por los miembros casi como semidioses, simbólicamente los convierten en súper humanos, al no concebir errores en ellos.

Los miembros regulares al creer que el poder ejercido por las autoridades de la iglesia viene de Dios, obedecen cualquier mandato de ellas, haciendo que éste se vea acrecentado y afianzado en los miembros, convertidos en objeto y blanco de este poder. La mecánica de poder, a la cual entran estos miembros los explora, desarticula y recompone; las altas esferas de la iglesia los llevan a que hagan lo 
Invest. pens. crit.

Vol. 3, No. 2, mayo-agosto 2015

pp. $32-52$

que ellos desean, para que operen como quieren, con las técnicas, rapidez y eficacia que se espera de ellos; siempre bajo el lema, es lo que Dios quiere para ti, o el Señor me dijo estas palabras para ti, entre otras (Foucault, 1975).

Como puede notarse, la iglesia evangélica funciona como una estructura social caracterizada por una serie de construcciones relacionales que determinan sus propias dinámicas socio-culturales. La disciplina, foco de atención de este análisis, es uno de los procesos sociales que develan cómo la estructuración del control ha ido penetrando en los cuerpos simbólicos, delineando lógicas diversas y encontradas en torno a la representación y práctica disciplinaria en las congregaciones cristianas evangélicas.

La disciplina, vocablo comúnmente utilizado en las iglesias evangélicas “es el proceso de instrucción y corrección que Dios utiliza para con su pueblo o una persona" (Lockward, 1999, p. 300); ésta se aplica a aquellos miembros a quienes se les reconozca una falta que haya sido observada, declarada o denunciada. El liderazgo de la Iglesia con la finalidad de alcanzar dicho propósito, diseña y establece un sistema que los ayude a regularizar la vida del cristiano evangélico; surgen procedimientos, pautas, penas, tiempos que en conjunto forman al sistema disciplinario evangélico, el cual actúa como un sistema tecnológico de control sobre el espíritu (Foucault, 1975).

El diseño del sistema disciplinario, de mano del liderazgo evangélico, devela el sentido subjetivo humano presente en la dinámica disciplinaria, de carácter supuestamente espiritual, ya que entre otras cosas, cuando la falta es cometida por alguno de los miembros de la congregación, el sistema se activa, apareciendo en escena una serie de pecados enlistados, que llevan a justificar las acciones que los lideres toman para corregir al miembro pecador. La noción de disciplina manejada, es asumida como una experiencia espiritual que se evidencia en el cuerpo. En otras palabras, el fin principal de la disciplina en La Biblia, es la restauración del espíritu del hombre, los líderes aplican sanciones que castigan el cuerpo o la carne, creyendo que a través de éste se santifica el espíritu, el hermano-miembro pasa tiempo cumpliendo su penitencia, para poder alcanzar la santidad que se predica en los púlpitos. Mismo es, siguiendo los planteamientos foucaultianos, lo que persigue el control y la disciplina es la completitud de la asepsia social de aquellas desviaciones morales-espirituales que detentan contra el orden moderno de la sociedad (De Avila, 1993; Foucault, 1992).

Lo anterior lleva a los líderes a creer que deben controlar cada detalle relacionado con la conducta de los miembros de sus iglesias, se convierten en vigilantes perennes de la vida espiritual de los feligreses, más aún con aquel que pecó y fue sometido a la disciplina; desde los antecedentes, pasando por el acto en sí, hasta llegar al proceso disciplinario. Para los disciplinarios ningún detalle es insignificante al momento de establecer la pena apropiada para el pecador, "la minucia del reglamento, la mirada puntillosa de los inspectores, la sujeción a control de las menores partículas de la vida y del cuerpo" (Foucault 1975, p. 144), llevan a los líderes a ejercer mecanismos de control dentro de la iglesia, que regulan cada uno de los aspectos que conforman la vida, no solo del disciplinado sino de la congregación en su totalidad. 
En concordancia con Foucault (1975), la noción de disciplina en las iglesias evangélicas, implica una coerción constante, sin interrupciones, la cual ejerce el control hasta del más mínimo detalle, estando atenta a los procesos más que a los resultados que se puedan obtener; garantiza inexorablemente la sujeción constante de los que son sometidos a ella imponiéndole una relación de "docilidad-utilidad". Fabrica, en palabras de Foucault, cuerpos dóciles, que pueden ser sometidos, utilizados, transformados y perfeccionados mediante la corrección y la modificación de la conducta (Albujas, 2000; Fair, 2010).

Los líderes evangélicos creen, que su tarea es, el velar por la salvación y por la santidad, traducida en conducta, de aquellos que están dentro de la congregación, se les olvida que el trato de Dios con el hombre es personal, la salvación no se alcanza en grupo, por ende la santidad tampoco. En torno a ello, se produce una herida en la moral de quien recibe la disciplina, pues es sancionado en una de las estructuras más íntimas de su ser, su espíritu; sin embargo, la determinación tecnológica del castigo opera directamente sobre el cuerpo.

En medio de esto, es interesante preguntarse qué sucede con el ser humano cuando es sometido a estos mecanismos de control; cómo queda ante tal experiencia como humano y cristiano. A diferencia de sus líderes, la disciplina para el miembro regular es una experiencia espiritual y humana, pues encarna las consecuencias que trae consigo el ser disciplinado, creyendo que si sigue las instrucciones, será restaurado delante de la Presencia de Dios y de la iglesia, aunque la Palabra de Dios, en la cual basan toda su doctrina, afirma que una vez que cualquiera de sus hijos se arrepiente y le pide perdón, con un corazón sincero, Éste lo perdona de manera inmediata.

El liderazgo evangélico admite, que el Señor perdona de una vez, que las deudas contraídas con Dios se saldan con arrepentimiento, pero al referirse a la situación del disciplinado en relación a la iglesia como Institución, la situación cambia; el que esté arrepentido, no lo exime de la paga de la culpa, entendida como suspensión temporal de las actividades propias de la vida evangélica activa. La conclusión, a la que pareciera, que estos líderes llegaran es absurda, el hombre está preparado para las realidades del cielo, pero no para sus símbolos en la tierra, mucho menos para trabajar en la iglesia, pudiera pensarse que se tomaran en cuenta otros factores no cubiertos por la propiciación del Hijo de Dios; la pena ante la iglesia, a diferencia de Dios, se paga con meses de exclusión; lo que resuelve el pecado ante Dios, es el arrepentimiento, no el tiempo que pase sentado en una banca (De Avila, 1993).

Se hace claro que el reconocimiento y la aceptación del otro como "mi legitimo otro", traducido en respeto mutuo, está ausente en las relaciones establecidas entre los que aplican la disciplina y los que la reciben, pues esta se inscribe en un sentido no social del relacionar (Maturana, 2005, p. 14). Lo que predomina es una relación fundada en una búsqueda de dominación, en la negación del otro, donde el disciplinario deja de ser un rato hermano en Cristo y entra a ser la mano que operacionaliza la disciplina, en la que su verdad es única y absoluta. En palabras de Maturana, "el camino explicativo de la objetividad sin paréntesis" es lo que funda este mecanismo de relaciones no sociales, pues supone un sentido semiótico de realidades objetivadas y absolutas que se contraponen con el devenir ético de la racionalidad subjetivada y socialmente dispuesta. 
Invest. pens. crit.

Vol. 3, No. 2, mayo-agosto 2015

pp. $32-52$

En todo caso, el proceso disciplinario está impregnado de dinámicas psico-sociales producidas en la interacción simbólica fundada en el marco de la constructividad intersubjetiva del sentido común y de los saberes socialmente producidos. Desde esta perspectiva, las dinámicas del disciplinamiento se comprenden desde la misma fenomenología producida en la representación del modo de vida evangélico, por lo cual sigue siendo predominante en esta definición de problematizaciones, la vivencia misma de la disciplina desde la cotidianidad evangélica.

Las dinámicas del disciplinamiento se muestran en La Biblia, la cual contempla un proceso que "debe" seguirse al momento de disciplinar a un miembro de la congregación, para evitar conflictos posteriores (Mateo 18:17). El proceso bíblico contemplado en el pasaje no es seguido por las iglesias, el salto de etapas, y la convocatoria inmediata del miembro con testigos (directiva de la iglesia), para enfrentar cosas como, la decisión de su pena y los tiempos que debe permanecer inactivo en la Iglesia, es el pan diario en este proceso disciplinar. Dentro de este marco de referencia, se hace evidente la ignorancia hermenéutica que existe entre los que establecen la disciplina en la iglesia, el manejo que se le da al proceso disciplinario, puede calificarse como fuera de todo fundamento bíblico. Este sistema no es más, que la respuesta a la necesidad que existe por parte de los disciplinarios de ejercer mecanismos de control sobre los miembros (De Avila, 1993; Manzanero-Márquez, 2006).

Dentro de esta mecánica disciplinaria, un elemento que resalta es la función de algunos miembros de la iglesia, como vigilantes perennes de lo que ellos consideran es el correcto andar espiritual de un hermano en Cristo. Esta particularidad del proceso disciplinario evangélico, es similar a la figura del panóptico de Bentham tomado por Foucault en su texto Vigilar y Castigar (1975). Al respecto Quevedo (2001) señala que el panóptico "sitúa los cuerpos en el espacio en relación de unos con otros, de modo que los sujetos bajo vigilancia no saben cuando están siendo vigilado, y así hacen de policías para sí mismo con gran efectividad” (p. 88). En palabras de Albujas (2000), la intención de la vigilancia es determinar la pertinencia del castigo o cualquier proceso técnico de control, de cara a sanear las estructuras sociales afectadas por los desvíos producidos en el cuerpo.

Para los miembros de estas congregaciones, la iglesia se convierte en un emplazamiento funcional donde la disciplina organiza un espacio analítico, estableciendo presencias y ausencias, midiendo cualidades, vigilando, sancionando las conductas e instaurando comunicaciones útiles. La directiva de la iglesia controla, hasta el más mínimo detalle de la vida de sus miembros, dentro y fuera de la congregación, para ellos ningún detalle es indiferente. Desde esta perspectiva, la vida del feligrés en la iglesia no es fácil, sobre todo si se está en una posición pública dentro de ella, es decir, si se está en un altar que te hace vulnerable ante la mirada del líder (Foucault, 1975).

De todo lo expuesto se desprende la necesidad de estudiar la disciplina evangélica como mecanismo de control y poder dentro de las iglesias protestantes, analizando desde la perspectiva de sus miembros, los elementos, dinámicas y razones por las que este proceso marca significativamente el ser evangélico en la actualidad. 
Invest. pens. crit.

Vol. 3, No. 2, mayo-agosto 2015

pp. $32-52$

\section{Materiales y Métodos}

Construcción metodológica de la disciplina evangélica, entre escenarios, momentos e informantes.

La comprensión de los escenarios y fenómenos que envuelven al ser humano, el movimiento creado y delineado por él, el diseño de sus espacios, debe ser el punto de partida para todo investigador que tenga como propósito estudiar reflexivamente las realidades cotidianas, presentadas como un mundo intersubjetivo, compartido con otros, donde el joven evangélico, se encuentra a sí mismo en constante interacción y comunicación con el otro. Las vivencias que a diario experimentan estos jóvenes, generan y modifican sus realidades, determinando el modo a través del cual la investigadora se aproxima a la disciplina como fenómeno social (Berger y Luckman, 2001; Manzanero-Márquez, 2006; Marshall y Rossman, 2010).

Esta investigación, se centra en la necesidad imperante de un enfoque humanista para entender y reconstruir la realidad social que se estudia. Para tal fin, se hace necesario tomar como base fundamental los principios generales de la investigación cualitativa, planteados por González (2000), a partir de los cuales se asume el conocimiento como producción constructiva-interpretativa, así como el carácter interactivo del proceso de producción del conocimiento y la significación de la singularidad como nivel legítimo de la producción del conocimiento.

Dentro de las características predominantes de la investigación, se encuentra que es flexible, abierta, emergente, dinámica ya que estudia la disciplina evangélica como una realidad social, que es cambiante, versátil, inundada de informaciones, experiencias y prácticas de los actores involucrados; por tanto se hace imposible establecer un modelo estático, rígido que enmarque la investigación. De allí que se asuma como paradigma rector del estudio, el cualitativo de corte fenomenológico. La interacción permanente entre los actores y la investigadora, posibilita que la dinámica que emerge de su relación, descubra y modifique intenciones, propósitos y construcciones en la investigación, permitiendo la creación teórica de la realidad plurideterminada, distintiva, irregular, interactiva que presenta la subjetividad humana (Berger y Luckman, 2001; González, 2013; Martínez, 2013; Packer, 2013).

La utilización de un enfoque fenomenológico, que facilite la articulación de momentos, escenarios y actores, se hace necesaria; más aún cuando la investigadora conoce y comparte la creencia fundamental en la cual se basa el Evangelio. Por tanto, dejar a un lado las interpretaciones propias acerca de la disciplina evangélica, estudiarla tal y como se percibe en la realidad, es una de las condiciones para llevar a cabo la investigación. Se establece una relación dialéctica de co-implicación en la construcción del fenómeno, ya que se parte de una estructura propia que lleva a la reflexión del mundo hallado, el cual es, en palabras de Merleau-Ponty (1975), el ámbito natural, el campo de los pensamientos y percepciones. La fenomenología permite comprender la esencia de la disciplina evangélica, qué la caracteriza y la hace única e irrepetible. Es volver a las cosas mismas, como afirma Sandín (2003), a las vivencias, a aquellas percepciones que junto con las interpretaciones, producen significados, valores y propósitos. 
Invest. pens. crit.

Vol. 3, No. 2, mayo-agosto 2015

pp. $32-52$

Los actores, son los protagonistas del estudio al construir y determinar sus propias realidades epistemológicas, conformando una entidad compleja y cambiante, que determinan la manera que quieren ser vistos, comprendidos y analizados. La investigadora entra en una situación cara a cara (investigador-investigado), donde uno se le aparece al otro en un presente vivido compartido por ambos, buscando un intercambio continuo entre expresividades y subjetividades; esta relación se concibe como un hábitat de sentido, que no depende de elementos exteriores para su existencia, se deleita en su propia comunicación; crea y consume sus propios símbolos y significados partiendo de las interpretaciones construidas entre ambos. Esto permite aprehender éticamente los procesos necesarios a la hora de responder las preguntas de investigación que se hayan planteado (Berger y Luckmann, 2001; González, 2013; Maxwell, 2013; Montero, 2010).

En esta investigación, el proceso de selección de escenarios, momentos e informantes, es intencional, ya que como plantea Maxwell (2013) "es una estrategia en la cual los escenarios, las personas, o eventos particulares son seleccionados deliberadamente con el fin de proveer información importante que no puede ser obtenida por otras opciones" (p. 71; traducción propia). La necesidad de construir el fenómeno desde la perspectiva del miembro implicado en el proceso disciplinario, lleva inexorablemente a la escogencia de este proceso de selección. Es así, como el escenario seleccionado para efectuar la recolección de información fue una iglesia evangélica de la ciudad de Maracaibo, Venezuela, que reuniera criterios tales como: a) más de cinco años de fundada; b) reconocida en la ciudad como institución religiosa; c) con un reglamento interno establecido que incluyera normas disciplinarias; d) contar con un Comité de ética o disciplinario que dirigiera el proceso disciplinario en la iglesia.

Para el grupo de informantes clave, se toma en cuenta que los mismos estuvieran situados de manera próxima e inmediata al fenómeno, sin intermediarios de información, ni de sentido; caracterizados por su singularidad y por riqueza en la información provista, así como por la intensidad de la experiencia vivida en o para el fenómeno (González, 2013; Manzanero-Márquez, 2006). Por tanto, los actores sociales escogidos, tienen como característica principal, ser miembros líderes, activos en la congregación, así como los siguientes criterios: a) creyentes en Jesús como Señor y Salvador; b) mayores de edad; c) con más de cinco años de convertidos al evangelio; d) Conozcan el proceso disciplinario. Es importante resaltar que dentro del grupo de informantes clave, la mitad fueron disciplinados, mientras que la otra la mitad, no.

Los métodos de recolección de información, son los medios necesarios para responder las preguntas de investigación, por ello la utilización de las entrevistas focalizadas, permiten conocer desde sus actores el significado de la disciplina evangélica; además de plantear reciprocidad metodológica. De igual forma se considera la observación directa, ya que busca complementar la información que se obtenga en el proceso de entrevista; ésta facilita el entendimiento de momentos que son claves para la comprensión de lo dicho en la entrevista, así como elementos de la perspectiva que el actor no mencionó al momento de ser entrevistado (Maxwell, 2013; Marshall y Rossman, 2010; Ruiz, 2012). 
La entrevista se concibe como "conversaciones con un propósito", donde se plantean temas que facilitan al actor, opinar sin irrespetar la forma como estructura y encuadra su respuesta; desde la interacción se crean y captan significados (Kanh y Canell, 1957; citado en Marshall y Rossman, 2010; Ruiz, 2012). Las preguntas de la entrevista, son consideradas generadoras ya que ofrecen al entrevistado la libertad para establecer las relaciones entre situaciones que lo llevan a construir y asumir la experiencia vivida como propia; de ahí que se considere está técnica como semi estructurada, las preguntas bases producen otras en el desarrollo de la misma. El guion de entrevista estuvo conformado por las siguiente preguntas: a) ¿Cuál ha sido tu experiencia en la iglesia evangélica? b) ¿Cómo es la disciplina evangélica? c) ¿Cuál es la base de la disciplina evangélica? d) ¿Cómo es el proceso de disciplinamiento en la iglesia evangélica? e) ¿Quiénes aplican la disciplina en la iglesia evangélica? f) ¿Qué opinas de la disciplina evangélica?

Una vez realizadas las entrevistas, transcritas y categorizadas se utilizaron ayudas visuales (matrices y tablas) como estrategia analítica adicional; éstas permiten a la investigadora el establecimiento de relaciones entre unidades discursivas, categorías y posteriormente temas de investigación. Las categorías, se asumen como "émicas", ya que son tomadas de la estructura conceptual de la gente que facilita la información, admiten el encuentro de los discursos con los conceptos teóricos necesarios para explicar el fenómeno estudiado. Es importante señalar que en el discurso de los evangélicos, se devela la compleja red de relaciones que en torno a la disciplina existe, por tanto éste se asume como consecuencia de experiencias, de realidades que los rodean y los marcan como protagonistas de su historia (Farías y Montero, 2005; Graizer, 2013; Maxwell, 2013; Van Dijk, 2003).

El análisis crítico del discurso es entonces el empleado para dilucidar los problemas político-sociales inmersos en el fenómeno, ya que su objetivo principal es conocer de qué manera el discurso favorece a la reproducción de la desigualdad y la injusticia social estableciendo, quiénes tienen acceso a estructuras discursivas, de comunicación, admisible y legitimado por la sociedad. Permite develar dentro de la Iglesia Evangélica, la construcción socio-simbólica que en torno a la disciplina hacen los jóvenes entrevistados. A fin de elaborar este tipo de análisis, donde se devele la dimensión discursiva del abuso del poder, de la injusticia y la desigualdad, se toman en cuenta los siguientes criterios: a) Buscar la crítica generalizada de aquellos actos que se repitan y no sean aceptados por los miembros de la iglesia; b) Indagar por las críticas estructurales que se relacionen con la Iglesia y los diferentes grupos que dentro de ella están, más que buscar señalar a alguna persona en específico; c) Evidenciar en hechos concretos y actitudes, el abuso de poder y la dominación que sean inaceptables para los miembros de la congregación (Foucault, 1975; Van Dijk, 1999). 
Invest. pens. crit.

Vol. 3, No. 2, mayo-agosto 2015

pp. $32-52$

\section{Resultados}

Construcción de significados desde sus actores, de las Tecnologías de control y poder en la disciplina evangélica.

La disciplina evangélica es un sistema de corrección e instrucción instaurado por el Señor Jesucristo, para la formación del carácter espiritual de Su pueblo. Desde la perspectiva de los evangélicos, la disciplina está determinada por los aspectos funcionales que la estructuran, por las construcciones de significados contextuales, las concepciones sobre la estructuración, su sentido humano y espiritual y las dinámicas psico-sociales implícitas en el proceso. Para los entrevistados, existen dos concepciones sobre este sistema, la disciplina bíblica-espiritual y la humana-eclesiástica. La primera es considerada como un sistema de corrección basado en el amor y la reflexión de Dios, para formar y moldear el carácter del hombre; es una muestra del amor de Dios. Su propósito principal es restaurar al ser humano en ciertas áreas específicas, es un momento de restauración, de encuentro o de reconciliación con el Señor.

"Bíblicamente, la disciplina es un proceso por el cual todo cristiano debe pasar, porque afina, este, nuestra convicción y nuestra conducta como cristiano, bíblicamente es eso. Forma parte de un sistema de corrección, de corregir nuestros propios errores. La disciplina, se entiende también bíblicamente, como parte de ese proceso de formación de Dios del carácter del hombre, básicamente eso" (Hombre, 28 años. Lic. En Educación. Líder de Crecimiento Espiritual).

"La espiritual, es la que Dios establece en la Biblia, la que encierra de repente una exhortación, pero una exhortación basada en amor, donde la persona realmente siente que hizo algo pero se llama a la reflexión y cambia su forma caminar" (Mujer, 30 años, Comunicadora Social, Ministro de Adoración y Alabanza).

La disciplina humana-eclesiástica, es entendida como un mecanismo oculto que mata al ser humano, pues implica duro trato al cuerpo, sin la atender las esferas espirituales; este tipo de disciplinamiento condena y castiga, de manera personal y persistente la culpa del pecador; es una consecuencia conocida en la iglesia de los errores cometidos por el disciplinado, éste se encuentra a si mismo sin ningún apoyo por parte del líder, en un proceso que debería de restauración.

"porque si bien es cierto, vamos a partir de una parte espiritual, la Biblia dice, aún el pecado se corrige con amor y misericordia, es incongruente tener un tipo de disciplina que mate al ser humano a nivel emocional, a nivel individual, psicológico y que todavía estemos profesando qué?..."En cambio, el castigo humano, la disciplina humana es la que..., como lo dice también la Biblia, que muchas veces nosotros colocamos disciplinas, no es la palabra textual, pero se colocan disciplinas, normas, que son duro trato al cuerpo, pero que en nada llevan a una espiritual real; entonces ese tipo de disciplina es la humana, la que tú no vas a hacer eso, porque yo lo digo" (Mujer, 30 años, Comunicadora Social, Ministro de Adoración y Alabanza). 
La disciplina es considerada, un proceso de índole separatista, denigrante y carente de pruebas, que ha tenido trascendencia histórica en vida de la iglesia; la misma ha sido clasificada por los entrevistados, como un proceso dañino, que no admite el concepto bíblico de la restauración del miembro, pues se centra en la justicia de Dios, omitiendo Su amor, los cuales bíblicamente no pueden estar separados. Algunos, aún fuera de su experiencia, la consideran como injusta y afirman que el fin último es castigar al hombre y separarlo un tiempo de sus actividades regulares en la iglesia. Las discrepancias entre ambos conceptos disciplinarios, trae dudas en los actores sobre la verdadera aplicación de los principios bíblicos en la disciplina eclesiástica, por ejemplo diferencias en las concepciones del perdón, el de Dios y el del hombre, la separación de las actividades propias de la vida religiosa activa en la eclesiástica, en contraste con el carácter correctivo en la bíblica, entre otras.

"Pero eso, lo que ha causado es mucho daño, en muchas vidas y lo que han hecho es irse, o sea, irse por lo menos de la iglesia. Muchos han buscado congregarse y reunirse en otras iglesias...Entonces, es muy denigrante el proceso porque sin pruebas, hasta sin pruebas te sientan. Dan por sentado que es culpable” (Mujer, 29 años, Ingeniero en Computación, Ministro de Adoración y Alabanza).

"No hay nada mejor que el verdadero amor, hablar de una forma bien, de ser bien, para llevar a la persona al arrepentimiento, yo considero que de esa manera debería ser la disciplina“(Mujer, 27 años, Vendedora de ropa, Miembro regular y Ex líder juvenil).

"Ahora a nivel eclesiástico, la disciplina es ese elemento, que si se quiere no va a ser tan dirigido hacia la corrección, sino hacia, por lo menos en el caso de acá, no es tanto la parte de corrección, como entendido, como de restauración, sino de eliminación...porque básicamente no existe el otro proceso bíblico, que se da junto con la disciplina, que es la restauración...Por ejemplo, si tienes cargos dentro de la iglesia, se te quitan los cargos de la iglesia, dependiendo la falta, pues se te quitan los cargos de la iglesia hasta que restituyas la falta" (Hombre, 28 años. Lic. En Educación. Líder de Crecimiento Espiritual).

Las diferencias existentes entre los dos tipos de disciplinas, son evidentes, a pesar de que la Biblia es el único fundamento básico para los evangélicos, éstos al ejercerla en la iglesia le dan mayor importancia a lo que decidan o piensen los que se encargan de aplicarla, más que a la misma Palabra de Dios. La disciplina es entonces definida por un hombre, el pastor, el cual junto a los ancianos (directiva de la Iglesia), diseñan la normativa que la rige, conformándose a sí mismos en las autoridades disciplinarias que dirigen el proceso. Afirman los actores que esta normativa no es conocida por todos en la iglesia, algunos de ellos aseguran la existencia de las normas, pero sostienen que las mismas no contemplan el control del tiempo de disciplinamiento, pues es prerrogativa de la autoridad decidir cuánto tiempo un hermano-miembro debe estar separado de sus funciones en la iglesia.

"eso lo define un hombre y no debería ser así...En la iglesia disciplinan desde los ancianos, este los ancianos son los que he visto yo, que disciplinan, y por supuesto con conocimiento del pastor..." (Mujer, 29 años, Ingeniero en Computación, Ministro de Adoración y Alabanza). 
Invest. pens. crit.

Vol. 3, No. 2, mayo-agosto 2015

pp. $32-52$

A pesar de existir un comité de ética, los miembros afirman que en su iglesia, la vigilancia de la moral y la ética está a cargo de una sola persona, según las consideraciones que ésta haga, el caso es llevado al pastor para definir el tipo de disciplina debe aplicarse. Los casos de disciplinamiento manejados personalmente por el pastor, son los que involucra a las autoridades de la iglesia, generalmente a lo que ancianos se refiere, y solo este tipo de casos se le da seguimiento en la iglesia, desde que peca, su restauración y reinserción en la vida evangélica, sin importar si hubo restauración o no; de lo contrario el seguimiento que se le hace al disciplinado en casi nulo, por lo que comentan que luego del cumplimiento del castigo impuesto, algunos siguen con una doble vida dentro de la iglesia, mientras otros se retiran.

"Bueno, aunque tengo entendido, inclusive conocí hace poco que hay un anciano de moral y ética... ¡Correcto! La muchacha que anda con escote, él muchacho que anda con gorra o algún piercing por ejemplo, algo que este según el fuera de la moral y de la ética" (Mujer, 29 años, Ingeniero en Computación, Ministro de Adoración y Alabanza).

"Específicamente, algunos casos los manejan ellos, otros los manejan a nivel pastoral, me imagino que es cuando son los ancianos...Después de esos seis meses, por ejemplo, tú vuelves y puedes seguir con tu vida doble, no hay problema, porque ya tu pasaste por la disciplina, ya pasaste por los seis meses, ¿sí? Que es lo que yo hablaba anteriormente, que es un período de restauración” (Mujer, 36 años, Locutora y Productora de Radio y Televisión, Ex líder de la iglesia).

"Después toman la decisión, y cuando toman la decisión los llaman y ahí, si les dicen pues que estás en disciplina "por esto por esto y por esto", pero no lo controlan; bueno, no he sabido de casos, que lo llaman para ver como esta su vida, no, es más, he sabido de casos que se van de la iglesia y quedan en disciplina perenne" (Hombre, 24 años, Lic. En Educación, Ministro de Adoración y Alabanza).

Lo anterior expuesto, devela las diferencias existentes en la aplicación de la disciplina dentro de la iglesia evangélica. Los actores afirman que los criterios manejados para el disciplinamiento, son generalmente el tipo de falta cometida, el nivel o la posición que tenga el disciplinado, pero sobre todas las cosas, las relaciones que el disciplinado tenga establecidas con las autoridades de la iglesia. La disciplina eclesiástica se convierte en una acción clientelar, injusta; un proceso selectivo, donde el miembro idóneo es aquel que practica obediencia absoluta al líder, en palabras de los actores este proceso es aplicado a "bobos" y conlleva a una mala experiencia, el término bobo es utilizado para aquellos que se encuentran en desventaja con otros, ya que como miembros regulares no tienen amistades con las esferas de poder de la iglesia evangélica.

"así como hay otra que no, simplemente porque hay rumores infundados, o porque lo que sea, que es donde yo veo que está el problema, que no se siguen los mismos parámetros con las mismas personas... Si, eres conocido de la gente que...Jajaja, que va a poner la disciplina, si eres hijo de un anciano, si eres alguien de los pesados, vamos a 
tenerte un poco de consideración" (Mujer, 30 años, Comunicadora Social, Ministro de Adoración y Alabanza).

"O sea, para los que no tienen amigos en altos cargos, yo creo que es así. También considero que hay no justicias, y también creo que no hay oportunidades, no te dan oportunidades cuando de verdad no sois hijo de alguien o no sois amigo de alguien, como me pasó a mí. Por lo que a mí me paso es por lo que te digo eso... Yo creo que lo malo que me ha pasado es, que la disciplina no es para todos en la iglesia, yo no creo que sea para todos, para un grupo seleccionado, o sea yo creo que para los más bobos" (Mujer, 27 años, Vendedora de ropa, Miembro regular y Ex líder juvenil).

Las autoridades disciplinarias son consideras por el actor como poco espirituales, que actúan creyéndose Dios, y por ende sus decisiones son consideradas, por ellos mismos como de parte de Dios. La necesidad del líder evangélico de madurar espiritualmente, es imperante para éstos, ya que consideran que no están preparados para escuchar los pecados de los otros, ni para aplicar una verdadera disciplina, afirman que darán cuenta a Dios de cada una de sus acciones.

"Si ellos fueran más espirituales, no te juzgarían, no dieran por sentado que estas en pecado, porque ellos no lo saben, a menos que te vean o te vieran. Ah bueno, porque definitivamente deben creerse Dios... que yo tenga entendido, solamente el Señor es el que conoce nuestro corazón, jah pero ellos también! jaja. Definitivamente ellos también, o por lo menos dan por sentado eso" (Mujer, 29 años, Ingeniero en Computación, Ministro de Adoración y Alabanza).

Según los entrevistados, una vez que las autoridades conocen el pecado del hermano, lo cual es considerado como la condición para estar en disciplina, comienza el proceso, el cual es diferente para cada caso, por ejemplo si el hermano confiesa espontáneamente su falta, lo cual ocurre muy poco, se le ofrece consejería, sin entrar en la mecánica de disciplinamiento, si incurre nuevamente en la falta, se le disciplina; en otros casos dependiendo de la falta, se le considera al momento de determinar el tipo de procedimiento disciplinar por haberse presentado espontáneamente. Existen casos de algunos hermanos, piden entrar en este proceso por considerar que necesitan un tiempo apartado, para la reflexión personal y espiritual.

"Deberías estar en pecado para ponerte en disciplina; o sea, Jesús y la disciplina te debería corregir” (Mujer, 29 años, Ingeniero en Computación, Ministro de Adoración y Alabanza).

En cualquiera de los casos, disciplina implica separación de los ministerios y la suspensión de las actividades de la iglesia. Existen casos de disciplinamiento que el miembro desconoce que va a ser sometido a una disciplina, se da cuenta de ello, por el cese repentino de sus actividades eclesiásticas por las autoridades, y por el ofrecimiento de oportunidades futuras de trabajo en la iglesia. La suspensión como mecanismo disciplinar no informado, es una de las acciones más comúnmente empleada en la iglesia. 
Invest. pens. crit.

Vol. 3, No. 2, mayo-agosto 2015

pp. $32-52$

"Bueno, depende de los casos, te ponen en tela de juicio, porque la palabra es, "¡estáis sentao!" Por ejemplo, a los que estamos cantando, por ejemplo a los ministros de alabanza...Los que estamos cantando...Te suspenden de las actividades...Si fuese un, no sé, un miembro de la iglesia, que no participas activamente de las actividades, o que solamente te limitáis a reunirte, a asistir, a oír una predica y tal, no sé qué más, quizá no se dieran, no se dan cuenta de eso... (Mujer, 29 años, Ingeniero en Computación, Ministro de Adoración y Alabanza).

"Y es que, lo hacen demasiado evidente, lo hacen muy evidente. Hermana, por favor, ¡Dios le bendiga!, el año que viene, usted va a tener una oportunidad, "que no sé qué", "que no sé qué más", aparte que no estoy pidiendo oportunidad de nada...claro no me ha tocado, no sé porque. A mí nunca me dijeron, cuando tuve el problema, nunca me dijeron, estás en disciplina, no vas a hacer esto, no vas a hacer aquello, igual manera, me quitaron de todo, yo no podía trabajar en nada, pero a mí no me dijeron que estaba en disciplina...porque aparte de que te rayan, porque primero no se aseguran de que es verdad, o sea te llevan ahí y hablan todo y no es que te dan oportunidad de si o no, de lo hiciste o no lo hiciste, jno, vos lo hiciste, lo hiciste y ya!” (Mujer, 27 años, Vendedora de ropa, Miembro regular y Ex líder juvenil).

El proceso disciplinario se inicia, una vez que las autoridades dan credibilidad a rumores o comentarios no probados, asumen la culpabilidad inmediata del disciplinado, la ausencia de un comité evaluador que investigue sobre el asunto, se hace presente. El miembro, es llamado a una reunión disciplinar, la cual puede ser con las partes involucradas en el problema, o de forma individual, como las autoridades dispongan para ello. Comenzada la reunión, lo que sucede dentro de ella, si se ora o se lee la Palabra, es especulado por algunos, mientras que otros desde su experiencia afirman que fueron manipulados y acosados por las autoridades, para responder como se espera de ellos, sin tener en algún momento derecho a réplica. El fin último de este proceso, según los entrevistados, es el control absoluto de la congregación, una muestra del supuesto poder detentado por las autoridades.

"Lamentablemente en la iglesia, se rige mucho por los rumores, comienza el rumor se llama a la persona, en un consenso y muchas veces no se permite el derecho a réplica...la persona que va a consenso, va directamente a saber que va a ser puesto en disciplina, porque ya han predeterminado o preestablecido una disciplina para él... Entonces lo llaman y lo sientan, muy pocas veces llaman en consenso a las personas involucradas, sino que lo hacen individualmente" (Mujer, 30 años, Comunicadora Social, Ministro de Adoración y Alabanza).

"Era para hablar de alguien, y yo tenía que decirles a ellos, o sea, te hablan de una manera, te tratan de envolver, de manera que vos asumís de que estás pecando, y no lo hiciste, pero te envuelven de tal manera que terminas diciendo que si” (Mujer, 27 años, Vendedora de ropa, Miembro regular y Ex líder juvenil).

El disciplinado cambia de actor activo en la iglesia a receptor de información; la incertidumbre experimentada por él ante el proceso disciplinar, lo hace, sufrir, llorar, deprimirse; algunos se separan de la iglesia, confirmando el supuesto pecado cometido, creyendo que la disciplina que le fue impuesta viene 
de Dios; otros no sienten haber sido restaurados, que es el propósito principal de la disciplina; el resto actúan de forma indiferente ante el proceso. Los miembros de la iglesia evangélica valoran la experiencia disciplinar negativamente, y lejana de ser espiritual, afirman que es injusta y causa daño emocional, no solo al disciplinado, sino a sus familiares también, ya que como una bomba los impacta tal situación y los lleva a dejar de asistir al igual que él.

"No, pero el disciplinado es totalmente receptor de toda la información, pero no puede ser actor, ni nada, no puede actuar. Ni siquiera Santa cena, nada" (Hombre, 24 años, Lic. En Educación, Ministro de Adoración y Alabanza)

"He podido estar con varias personas, y varios han tomado actitudes completamente diferentes. Por ejemplo, unos de sufrimiento, o sea, lloro, me deprimo, me voy de la iglesia, este... no quiero saber más nada de Dios, se apartan completamente, como si fuera Dios realmente el que le estuviera imponiendo el castigo y lo estuviera desechando...Inclusive detrás de esos, están las familias de esas personas que están afectadas, porque uno nada más se detiene quizá en la persona y algunas veces hasta las familias de esas personas que, por ejemplo están siendo disciplinadas, ¡Dios mío!, eso les cae a ellos como una bomba, porque ellos quizá están viendo..." (Mujer, 30 años, Comunicadora Social, Ministro de Adoración y Alabanza)

Las decisiones disciplinarias, para estos actores carecen de fundamento bíblico, así como de elementos probatorios, ponen en tela de juicio el testimonio del hermano en la iglesia, lo que los lleva a tildar la situación experimentada como complicada. Afirman estar en desacuerdo con el proceso disciplinario, pues lo consideran equivocado e inadecuado; sostiene que la forma bajo la cual se aplica la disciplina dentro de la congregación, muestra la subjetividad implícita de aquel que la diseña, pues está fundamentada en la persecución del miembro, más que en una búsqueda de hechos. Las prácticas disciplinarias son consideradas, como teatro de control ético-moral, donde se ponen en riesgo, eventos como la conversión de un nuevo creyente; a pesar de que miembros con más tiempo en la iglesia aseguran la mejoría de estos mecanismos, el desacuerdo y confrontación con las autoridades, la oposición a los principios bíblicos, y la insatisfacción son elementos comunes cuando de la experiencia de ser disciplinado se refiere. Lo vivido los lleva a entender que es posterior a lo sufrido, donde podrían conseguir algún tipo de aprendizaje que los lleve a reflexionar.

“Ja, o sea, no es una persona este quizá es todo un grupo que se ve afectado por una decisión tomada tan a la ligera y con tan pocas bases, o con tan pocas pruebas, o con tan poco, hasta quizá con tan poco fundamento bíblico, este es fuerte, es complicado, es bien complicado...Es lo que el comité considere, es muy subjetivo. Por lo general, es muy subjetiva la disciplina, es dependiendo, no de los hechos reales, de lo que yo investigo, de lo que yo analizo, sino que se realiza con una especie de persecución" (Mujer, 30 años, Comunicadora Social, Ministro de Adoración y Alabanza).

La experiencia de ser disciplinado, está marcada para algunos actores, no solo por las prácticas y las autoridades disciplinarias, sino también por los otros miembros de la iglesia, que asumen una posición de vigilantes de la conducta del otro, pues se sienten involucrados al conocer secretos que no debían 
Invest. pens. crit.

Vol. 3, No. 2, mayo-agosto 2015

pp. $32-52$

saberse en primer lugar; comentarios y miradas en torno al disciplinado, muestran la dificultad de olvidar el error del disciplinado, por parte de miembros regulares. Este tipo de situaciones, produce en el miembro regular que sienta precaución ante el proceso, y en el disciplinado, sentimientos de malestar, y desanimo para seguir trabajando en la iglesia, por lo que algunos dejan de asistir. La letra escarlata, es una metáfora utilizada para identificarse como miembro disciplinado.

"primero porque estamos hablando de lo qué es la disciplina y como nos pudiera haber afectado, y con todo, porque yo pienso que todo va ahí, con la experiencia...Hay personas que están pendiente hasta de lo más mínimo de lo que vos hacéis para caerte con la cosa...Y miradas, miradas de que... o sea, acusadoras, de allá viene. Hay gente que comenta, cuando te ve, comenta...Yo he hecho comentarios de otras personas: que... yo me he enterado que ha hecho esto o ha hecho aquello. Por eso, te lo digo, porque yo lo he hecho. Y después me siento mal, me siento mal porque yo estuve en esa situación” (Mujer, 27 años, Vendedora de ropa, Miembro regular y Ex líder juvenil).

"No, siempre es... es como la letra escarlata, estás en disciplina y te la ponen. Si eres soldado raso" (Mujer, 36 años, Locutora y Productora de Radio y Televisión, Ex líder de la iglesia).

Ante tal situación, el disciplinado se preocupa por su imagen en la iglesia y procura resguardarla, la importancia de la discreción y la garantía de la intimidad del miembro, ante eventos disciplinarios son esenciales para no ocasionar daños en el ser humano. La disciplina para los actores debe tratar de no lacerar al hermano en Cristo, de no maltratarlo, y alcanzar el carácter correctivo que ésta debe tener, así como las consecuencias que de ella se espera; que la actitud cuando alguno cae, sea de oración y comprensión; de consuelo y compañía para el disciplinado.

"Debería ser en discreción, no... porque que se hable entre los ancianos y se diga, eso es dañar a la persona... no necesariamente, nosotros no nos tenemos que enterar, porque es intimidad de Él con Dios, porque es intimidad del anciano con el miembro de la iglesia. A eso me refiero, si hacen una reunión porque la persona está en disciplina, eso no debería salir de ahí, no debería salir" (Mujer, 27 años, Vendedora de ropa, Miembro regular y Ex líder juvenil).

"Pero de resto, considero que la disciplina es buena, siempre y cuando, no lacere al ser humano como individuo" (Mujer, 30 años, Comunicadora Social, Ministro de Adoración y Alabanza).

"Bueno, debería ser de corregir... Pero algo que no cause daño... o sea, yo lo veo así; como algo que no cause daño porque eso es lo que dice la historia, la disciplina normalmente no trae unas consecuencias... o sea, o no hace el efecto que debería" (Mujer, 29 años, Ingeniero en Computación, Ministro de Adoración y Alabanza).

Aunque muchos no habían escuchado el término disciplina en las enseñanzas de la iglesia, ni conocían el proceso de restauración implícito en ella, los evangélicos afirman lo único después de una disciplina es Dios, no los comentarios, ni las acciones de los demás, y proponen la modificación nominal del 
termino disciplina, por resultarle un poco incómodo, por período de reflexión, que quizá es lo que más identifica el deber ser, en tal proceso como tal.

'Yo no me acuerdo, que a mí me hayan hablado de la disciplina en las clases de crecimiento espiritual, ni en las clases de avanzada, ni en las clases de bautismo, a mí no me hablaron de esto...Yo te digo, cuando ella me hablo del proceso de la restauración, primera vez en mi vida que yo escuchaba eso" (Mujer, 27 años, Vendedora de ropa, Miembro regular y Ex líder juvenil)

"He aprendido, a tratar de que no me importen los comentarios de las personas, a tratar, de que no importen las actitudes de otras personas, sino que me importe Dios y yo. Mi relación con Dios y más nadie" (Mujer, 36 años, Locutora y Productora de Radio y Televisión, Ex líder de la iglesia)

\section{Discusión}

\section{$\underline{\text { Reflexiones finales en torno a la disciplina en la iglesia evangélica. }}$}

El encuentro de diversas lógicas, propio de las investigaciones cualitativas, han permitido que surjan construcciones sobre el fenómeno estudiado, la disciplina evangélica. Es de esta forma que elementos tales como, la visión de sí mismo que tiene el miembro dentro de la congregación; la demarcación de las autoridades en estructuras y conductas; la concepción del mundo propio a partir del fundamento bíblico, entre otros, se ven determinados por la acción disciplinar dentro y fuera de las Iglesias.

En primer lugar, el líder evangélico, se caracteriza por actuar según su estructura, su historia lo guía y envuelto en una falsa espiritualidad encamina a los demás a lo que el Señor, supuestamente a través de él habla. Por trabajar fuera de la voluntad de Dios, el funcionamiento de la congregación se ve afectado, y por ende todo aquel que le rodee. Las autoridades de la iglesia, más aun las disciplinarias, haciendo uso del discurso, emplean mecanismos de control y poder con los cuales exploran, desarticulan, y recomponen al miembro regular, no solamente para que este hagan lo que ellos desean, sino para que opere como se quiere, con las técnicas, la rapidez y la eficacia que se determina (Foucault, 1975).

Lo anterior devela, como las mecánicas de poder circulantes dentro la iglesia evangélica, se apoyan sobre los miembros, permitiéndoles a las autoridades, la utilización del tiempo y trabajo los feligreses. Estas tecnologías son ejercidas incesantemente a través de la vigilancia de la conducta de los miembros; supone más una cuadriculación compacta de coacciones materiales, un espacio analítico, en el que la disciplina codifica y dispone del espacio para funciones de control y de poder. En la iglesia evangélica, se evidencia el principio foucaultiano según el cual la verdadera y específica economía del poder trata de alcanzar de manera constante las fuerzas sometidas, la fuerza y la eficacia de quien las somete, en este caso las autoridades disciplinarias (Foucault, 1975; 1992). 
Invest. pens. crit.

Vol. 3, No. 2, mayo-agosto 2015

pp. $32-52$

Es de destacar que no todos los líderes actúan, ni son de la forma descrita, existen otros que obedeciendo el llamado de Dios en su vida, lo dejan todo por seguirlo, por lo que ellos dicen que es el cumplimiento del propósito de Dios en sus vidas; la construcción de templos, las grandes y pequeñas movilizaciones -campañas-, son los medios utilizados por éstos para la salvación de las almas. Estos líderes, pastores en su mayoría, tienen lo mencionado como proyecto de vida, lo que le da sentido a su existir. El servicio a Dios deja de ser un mandato y se convierte en su realidad, este tipo de liderazgo, más que ser causante de experiencias negativas para los miembros de las iglesias, es representativo del pastor de ovejas que hablaba David en los Salmos.

El pastor como figura de poder y autoridad principal dentro del Gobierno de la iglesia, dirige y controla, junto a los ancianos, todos los procesos que tienen a lugar dentro de la congregación. Sin embargo, en los casos de disciplinamiento, las decisiones sobre el qué hacer o cómo hacerlo depende de las personas involucradas en el hecho. Así, si los involucrados son autoridades, como ancianos o líderes importantes, la decisión la toma el pastor a puerta cerrada, con los que él quiera, si involucra a algún miembro regular que no tenga ningún cargo, la decisión la toma la comisión de ética. Estas decisiones por regla general afectan a algún miembro en la iglesia, a veces hasta varios. Algunos sostienen que la falta de madurez espiritual de estos "hermanos", es lo que hace que las decisiones y acciones de las autoridades les afecten; para ellos, poner la mirada en Cristo es ideal cuando de la convivencia se habla dentro una iglesia. Esta posición, denota la ligereza con que algunos miembros de la iglesia toman la posición y la realidad del otro.

La diferencia que existe en la aplicación de los mecanismos disciplinarios dentro de la iglesia, se hace evidente. Si eres miembro regular que fallo, y no tienes contacto con las autoridades, se aplica la disciplina en todo su rigor, el proceso de castigo impuesto, trae humillación, vergüenza, malestar, separación. Si por el contrario, formas parte de las autoridades de la iglesia y te equivocas, la disciplina cambia hasta de terminología, a diferencia de los anteriores, éste entra en un período de reflexión, donde el resguardo de la intimidad y del testimonio prima sobre lo demás, el correctivo que se le aplica por tanto, no trae consigo lo mencionados en los dos primeros casos. Lo que devela una relación estrecha entre disciplina y poder (Foucault, 1975; 1992).

Se hace necesario recordar las palabras del filósofo, cuando conversa que cada grupo o sociedad posee su régimen de verdad, la cual es producida gracias a múltiples imposiciones, produciendo efectos reglados por el poder; "define los discursos que los acoge y los hace funcionar como verdaderos; los mecanismos y las instancias que permiten distinguir los enunciados... la manera de sancionar a unos y a otros; las técnicas y los procedimientos que son valorados en orden de la obtención de la verdad, el estatuto de quienes se encargan de decir qué es lo que funciona como verdadero" (Foucault, 1999, p. 53).

La situación expuesta, devela de manera tácita, el carácter selectivo de la disciplina evangélica, muestra que el liderazgo evangélico, más que seguir los estatutos bíblicos para la aplicación de un proceso de restauración para el pueblo de Dios, siguen sus propias normas, y criterios viciándolo, manejándolo a 
su antojo y convirtiéndolo en lo que es hoy en día, una acción clientelar a favor de los más privilegiados fuera de la voluntad de Dios. La disciplina evangélica busca así fabricar cuerpos dóciles, sometidos y ejercitados, aumentando las fuerzas en términos económicos de utilidad y disminuyéndolas en términos políticos de obediencia; la relación foucaultiana que se planteaba al principio. Las autoridades evangélicas, más que pensar en el alma del disciplinado, piensan en la forma, de cómo estos mecanismos actúan en su beneficio, para el mantenimiento del control y el poder dentro de la iglesia (Foucault, 1975).

La decisión y la acción de las autoridades, afectan la vida espiritual y humana del miembro que se encuentra en una situación disciplinar, del disciplinado. Las implicaciones de vergüenza, desilusión, desánimo, rabia, que trae consigo el ser disciplinado, solo las conoce aquel que las vive, no la autoridad, ni el miembro, solo el disciplinado y algunas veces su familia. El legalismo, la vigilancia de la moral, son procesos que acompañan a la disciplina, y como proceso de restauración, como sistema de corección del ser humano, como se plantea en la Palabra de Dios, no es aplicado en la iglesia. La disciplina eclesiástica es un sistema de censura, de separación de la vida ministerial, es un régimen de castigo, que los líderes aplican tergiversando su propósito principal, con la única finalidad de controlar y manipular al miembro, para que funcione dentro de la iglesia, según sus condiciones y sus estatutos, en absoluta obediencia a lo que Dios según los líderes, tiene para el miembro.

La manipulación en la cual, lamentablemente, ha caído este sistema que fue establecido por Dios en Su Palabra para la restauración del pecador, es absurda; el propósito de Dios con la vida del hombre es infinito y no se ve afectado ni comprometido por nada. Es cierto que este sistema está concebido bíblicamente no solo para restaurar sino para depurar, en situaciones extremas a la iglesia, la diferencia radica en el hecho de que en las iglesias evangélicas, en condiciones y situaciones normales se aplican las medidas para casos extremos, sin importar que suceda con el afectado o con el disciplinado, lo que el sienta, después de la decisión no importa mucho, la penitencia que debe cumplir es lo que importa, y como el líder maneja la situación importa mucho más.

Los mecanismos que se activan luego de decidido el futuro del disciplinado en la iglesia, son originados en algunas ocasiones por falsas acusaciones, como afirmaron los jóvenes evangélicos. El rumor es el motor que activa el proceso disciplinario; llega a manos de una autoridad y ésta sin comprobar su veracidad, llama al implicado y lo lleva de una vez a una reunión con sus colegas disciplinarios, para decidir que va a suceder con él y cuánto tiempo debe permanecer en disciplina. Es de destacar que esta rutina se sigue solo cuando el disciplinado es un miembro regular, caso contrario cuando es una autoridad, el manejo que se hace de la situación es interna, pues lo que prima es resguardar la intimidad y el testimonio del hermano líder (Foucault, 1975; 1999).

La iglesia como casa de Dios, no está preparada, para escuchar el pecado del otro, el resguardo de la intimidad del disciplinado debe primar sobre la necesidad de querer compartir lo que Dios ha hecho con una vida, o del testimonio de cómo fue rescatado del pecado, que no es otra cosa que la necesidad imperante que tienen algunos de comentar al otro lo sucedido en secreto durante la reunión disciplinar, 
Invest. pens. crit.

Vol. 3, No. 2, mayo-agosto 2015

pp. $32-52$

aparte de irrespetar la privacidad de aquel que está siendo disciplinado. Si el disciplinado siente deseos de comentar, su pecado y los correctivos que le aplicaron, es su decisión y su vida, no decisión de los líderes y mucho menos de los hermanos que están en la iglesia, que con la excusa de querer orar por aquel que está en aflicción pretenden enterarse de cualquier cosa. Con el pretexto de velar por la espiritualidad en la congregación, los miembros asumen la posición de vigilantes perennes de ésta, traducida en conducta, cualquier detalle que consideren está fuera de lugar es reportado con un superior, con lo que comienza el proceso disciplinario (Foucault, 1975).

A pesar del abuso de autoridad de los líderes, de la actitudes de censura de los miembros, a pesar de todo lo expuesto anteriormente, es claro que para el evangélico, lo que permite sobrellevar la cotidianidad dentro y fuera de la congregación es la creencia en el amor del Dios que profesan; no los líderes, y sus disposiciones, ni los miembros y sus maneras. La fe en el plan de salvación de Jesús; la sangre derramada por Él, es lo que les permite funcionar y formar parte de la iglesia en la cual transitan la mayor parte de sus vidas.

\section{Referencias.}

Albujas, M. (2000). La docilidad como ejercicio político. En Albujas, M. y Duarte, F. (Comp.). (Comp.). Ética y Democracia. (pp. 75-97). Caracas, Venezuela: Monte de Ávila Editores Latinoamericanos.

Álvarez, J. (1987). Manual de la Historia de la Iglesia. Madrid, España: Publicaciones Claretianas.

Berger, P. y Luckmann, T. (2001). La construcción social de la realidad. Madrid, España: Editores Amorrortu.

De Avila, G. (1993). El purgatorio protestante. Florida, EEUU: Vida.

Fair, H. (2010). Una aproximación al pensamiento de Foucault. Biblioteca Jurídica Virtual del Instituto de Investigaciones Jurídicas de la UNAM. Disponible: http://www.juridicas.unam.mx/publica/librev/rev/polis/cont/20101/art/art2.pdf

Farías, L. y Montero, M. (2005). De la transcripción y otros aspectos artesanales de la Investigación Cualitativa. International Journal of Qualitative Methods, 4(1), Artículo 4.

Foucault, M. (1975). Vigilar y castigar. Argentina: Siglo Veintiuno Editores.

Foucault, M. (1992). Microfísica del poder. (3ª ed). Madrid, España: ediciones La Piqueta.

Foucault, M. (1999). Estrategias de poder. Tomo II. Barcelona, España: Ediciones Paidós Ibérica. 
Graizer, O. (2013). Estudios del Discurso Pedagógico y las recontextualizaciones: la perspectiva bernsteiniana para la investigación sobre políticas educativas. En Tello, Cesar (comp.) Las epistemologias de la política educativa: Enfoques y Perspectivas para el análisis de Políticas educativas. San Pablo, Brasil: Editora Mercado de Letras.

González, F. (2000). Investigación cualitativa en psicología. Rumbos y desafís. México: International Thomson Editores.

González, F. (2013). La subjetividad en una perspectiva cultural histórica: avanzando sobre un legado inconcluso. Revista CS, 11, 19-42.

La Santa Biblia. Revisión 1960. Nashville, EEUU: Colman Bible Publishers.

Lockward, A. (1999). Nuevo diccionario de la Biblia. Miami, EEEUU: Unilit.

Manzanero-Márquez, D. (2006). Construcción de la Disciplina Evangélica: Una aproximación fenomenológica desde la perspectiva de los jóvenes de la Iglesia Pentecostal (Trabajo especial de grado). Universidad Rafael Urdaneta, Maracaibo, Venezuela.

Maturana, H. (2005). Emociones y lenguaje en educación y política. (9ª Ed). Santiago, Chile: JC Sáenz Editor.

Marshall, C. y Rossman, G. (2010). Designing qualitative research. (5a . ed). EEUU: SAGE Publications.

Martínez, M. (2013). Nuevos paradigmas en la investigación. Venezuela: Editorial Alfa.

Maxwell, J. (2013). Qualitative research design. An interactive approach. Applied social research methods series. (3a . ed). EEUU: SAGE Publications.

Merleau Ponty, M. (1975). Fenomenología de la percepción. Barcelona, España: Ediciones Península.

Montero, M. (2010). Crítica, autocrítica y construcción de teoría en psicología social latinoamericana. Revista Colombiana de Psicología, 19(2), 177-199.

Packer, M. (2013). La ciencia de la investigación cualitativa. Colombia: Ediciones Uniandes.

Ruíz, J. (2012). Metodología de la investigación cualitativa. (5ª Ed.). Bilbao, España: Universidad Deusto.

Sandín, M. (2003). Investigación cualitativa en educación. Fundamentos y tradiciones. Madrid, España: McGraw Hill.

Quevedo, A. (2001). De Foucault a Derrida. Pasando fugazmente por Deleeuze y Guattari, Lyotard, Baudrillard. Pamplona, España: Ediciones Universidad de Navarra.

Van Dijk, T. (1999). Análisis crítico del discurso. Revista anthropos: Huellas del conocimiento, 186, 23-36. 
Invest. pens. crit.

Vol. 3, No. 2, mayo-agosto 2015

pp. $32-52$

Van Dijk, T. (2003). Ideología y discurso. Barcelona, España: Editorial Ariel.

Vila, S. y Santamaría, D. (1988). Enciclopedia Ilustrada de la Historia de la Iglesia. Barcelona, España: Clie. 